\title{
Mental health services for young people: matching the service to the need
}

\author{
Max Birchwood and Swaran P. Singh
}

\begin{abstract}
Summary
It is now known that the onset of severe and recurring mental health problems begins for the most part before the age of 25: this provides a clear focus for preventive strategies and public mental health that are a feature of many health policy frameworks. The present distinction between child and adolescent mental health services and adult services at 16 or 18 does not fit easily with these data and the now well-documented problems of transition suggest that a fundamental review of services for young people is
\end{abstract}

overdue. This supplement provides an overview of the epidemiological, conceptual and service structures for young people with emergent and existing mental health problems, and asks the question, 'How should we design services for young people to promote prevention and service engagement, and to improve outcomes?'

\section{Declaration of interest}

None.
Max Birchwood (right) is Clinical Director of Youthspace, Birmingham and Solihull Mental Health Foundation Trust, and Professor of Youth Mental Health, University of Birmingham. Swaran Singh (left) is Head of Division, Mental Health and Wellbeing, Warwick Medical School, and Honorary Consultant Psychiatrist, Birmingham and Solihull Mental Health Foundation Trust.

'The children now love luxury; they have bad manners, contempt for authority; they show disrespect for elders and love chatter in place of exercise. Children are now tyrants, not the servants of their households. They no longer rise when elders enter the room. They contradict their parents, chatter before company, gobble up dainties at the table, cross their legs, and tyrannize their teachers. You would agree with me? Yes.'

(Attributed to Socrates, probably from Plato's Republic, book 4)

This famous (possibly apocryphal) quotation tells us how adults have always found it difficult to understand the young, even though they have themselves not long since been members of the breed. Adolescence is a turbulent period of flux with a complex interplay between biological, psychological and social changes as young people navigate their way to adulthood, embark on career pathways, assume adult roles and responsibilities and develop sexual relationships. Parent-child conflict can develop and intensify as adolescents struggle for independence while still requiring support. In this supplement we learn of the paradox that although adolescence and early adulthood are a period of maximum physical health, ${ }^{1}$ it is a period with a steep rise in mental health problems. ${ }^{2}$ Prospective studies suggest that more than half of young people by the age of 21 years will have experienced one or more psychiatric disorders, ${ }^{3,4}$ with many starting in childhood. Although society is concerned with the healthcare needs of an ageing population, we also have overwhelming evidence that the foundation of lifelong mental health begins in childhood, particularly in adolescence - a time when emerging mental health problems are underrecognised and certainly undertreated. ${ }^{1}$ Recent large epidemiological studies have demonstrated that over three-quarters of serious mental health problems begin before the age of 25 years, with those that start later being delayed presentations or secondary conditions. ${ }^{2,5}$

In this supplement Lin et al and McGorry argue that many of these adolescent disorders are rather undifferentiated, polysymptomatic presentations that are capable of progressing to more traditional differentiated types with the passage of time and ongoing biosocial process; ${ }^{1,6}$ they call it the 'staging' model, taken from staging familiar in oncology. Lin et al outline the concept and the supporting evidence, ${ }^{6}$ and argue that this provides a framework for the study of developmental psychopathology and - crucially - for prevention and public health, currently high on the UK policy agenda. ${ }^{7}$

Current evidence strongly suggests that mental health problems presenting in adolescence increase the risk of disorder occurring in adulthood, ${ }^{2}$ hence providing a conceptual basis for early intervention, including a focus on high-risk groups. Stallard \& Buck and Chanen \& McCutcheon present two examples: Stallard \& Buck describe a successful pilot investigation to prevent depression in adolescents through a school-based intervention focusing on those at risk, ${ }^{8}$ and Chanen \& McCutcheon report on an early intervention approach for emerging borderline personality disorder in adolescents. ${ }^{9}$ This work builds on existing work developing early intervention in relation to eating disorders and the psychoses. ${ }^{1}$

\section{Matching service to need}

How best should we provide mental health support to our young people? For many years the international care model has distinguished the child and adolescent mental health service (CAMHS) pathway for those aged up to 18 years (or 16 years in some settings) from adult mental health services (AMHS). The developmental dimension described above broadly supports such a distinction, particularly if opportunities for prevention are realised. Singh et al, however, reported that the transition from CAMHS to AMHS is problematic for many adolescents, with a large proportion dropping through a care gap between the two services and losing much-needed continuity of care. ${ }^{10}$ Adolescents with a serious mental illness such as psychosis or bipolar affective disorder under CAMHS care do get referred to adult care, especially if in receipt of medication or admitted to hospital. However, young people with conditions such as attention-deficit hyperactivity disorder (ADHD), autism spectrum disorders, mild intellectual disability, emotional and neurotic disorders and emerging personality disorder are either not referred to adult care or if referred are not accepted. Those who do make the journey across services feel unprepared for the transition and the abrupt cultural shift from a child-centred developmental approach to the adult care model. It is perhaps for this reason that many disengage from adult services. For the majority, transition is poorly planned, poorly executed and poorly experienced. Singh et al reported that many felt overburdened and others felt 
abandoned by services. ${ }^{10,11}$ Clearly this lamentable state of affairs needs to be corrected.

The question then arises whether the problems with the CAMHS-AMHS distinction at age 16 or 18 years can be remedied, or whether we should consider it as fundamentally flawed and a structural impediment to care and treatment. Jones describes a steep rise in age incidence at this time, ${ }^{2}$ and McGorry et al argue therefore that 'the current system is weakest where it needs to be strongest.' ${ }^{1}$ McGorry et al challenge us to consider whether, if we were to design services now, we would propose the present structure or argue instead that a care pathway from age 12 years to 25 years best fits epidemiological data and clinical need. ${ }^{12}$ According to McGorry et al this would fit with international definitions of youth, and incidentally in the UK would align with local authority definitions. ${ }^{12}$

Lamb \& Murphy present a considered analysis of the current position and options from a CAMHS perspective. ${ }^{13}$ They argue that separate commissioning frameworks for CAMHS and AMHS potentiate discontinuities and are inimical to good care and effective use of resources. They raise critical questions about the future structure of services for young people and consider a number of potential options for service redesign. McGorry et al describe alternative service models from the different settings of Australia, Ireland and England. ${ }^{12}$ Neither the status quo nor these alternative models have clear evidence of efficacy; McGorry et al argue that the issue here is to agree on the criteria that need to be followed in designing such services, for example that they are aligned to evidence on epidemiology and age at onset and meet opportunities for prevention. ${ }^{12}$ These two papers, by Lamb \& Murphy and McGorry et al, together lay out the critical issues in reforming mental health services for our young people. ${ }^{12,13}$

\section{Concluding remarks}

In the UK a zeitgeist has emerged in government policy encouraging more systematic attention to public mental health and prevention, ${ }^{7}$ one that the Royal College of Psychiatrists has strongly endorsed. ${ }^{14}$ A consistent theme of the papers in this supplement is that we can realise this aspiration by a fundamental review and reform of mental health services for young people so as to give them (and us) the best opportunity to prevent lifelong recurrence. We hope that this supplement will trigger a much-needed debate about the future of services for our young people so that, unlike Socrates, we will no longer look upon them as a lost cause.

\section{Funding}

M.B. was part-funded by the National Institute for Health Research through the Collaborations for Leadership in Applied Health Research and Care for Birmingham and the Black Country.

\section{Acknowledgements}

We thank the Collaborations for Leadership in Applied Health Research and Care for Birmingham and the Black Country for their support of the Youth Mental Health Conference, Birmingham, 2010, on which this supplement is based.

Max Birchwood, DSC, School of Psychology, University of Birmingham, and YouthSpace, Birmingham and Solihull Mental Health Foundation Trust, Birmingham; Swaran P. Singh, MD, Division of Mental Health and Wellbeing, Warwick Medical School, University of Warwick, Coventry, and YouthSpace, Birmingham and Solihull Mental Health Foundation Trust, Birmingham, UK

Correspondence: Professor Swaran P. Singh, Division of Mental Health and Wellbeing, Warwick Medical School, University of Warwick, Coventry CV4 7AL, UK. Email: s.p.singh@warwick.ac.uk

\section{References}

1 McGorry P. Prevention, innovation and implementation science in mental health: the next wave of reform. Br J Psychiatry 2013; 202 (suppl 54): s3-4.

2 Jones PB. Adult mental health disorders and age at onset. Br J Psychiatry, 2013; 202 (suppl 54): s5-10.

3 Costello EJ, Angold A, Burns BJ, Stangl DK, Tweed DL, Erkanli A, et al. The Great Smoky Mountains Study of Youth: goals, designs, methods, and the prevalence of DSM-III-R disorders. Arch Gen Psychiatry 1996; 53: 1129-36.

4 Silva PA. The Dunedin multidisciplinary health and developmental study: a 15 year longitudinal study. Paediatr Perinat Epidemiol 1990; 4: 96-127.

5 Kessler RC, Chiu WT, Demler O, Merikangas KR, Walters EE. Prevalence, severity, and comorbidity of 12-month DSM-IV disorders in the National Comorbidity Survey Replication. Arch Gen Psychiatry 2005; 62: 617-27.

6 Lin A, Reniers RLEP, Wood SJ. Clinical staging in severe mental disorder: evidence from neurocognition and neuroimaging. Br J Psychiatry 2013; 202 (suppl 54): s11-7.

7 Department of Health. No Health Without Mental Health. Department of Health, 2011.

8 Stallard P, Buck R. Preventing depression and promoting resilience: feasibility study of a school-based cognitive-behavioural intervention. Br J Psychiatry 2013; 202 (suppl 54): s18-23.

9 Chanen AM, McCutcheon L. Prevention and early intervention for borderline personality disorder: current status and recent evidence. Br J Psychiatry 2013; 202 (suppl 54): s24-9.

10 Singh SP, Paul M, Ford T, Kramer T, Weaver T, McLaren S, et al. Process, outcome and experience of transition from child to adult mental healthcare: multiperspective study. Br J Psychiatry 2010; 197: 305-12.

11 Paul M, Ford T, Kramer T, Islam Z, Harley K, Singh SP. Transfers and transitions between child and adult mental health services. Br J Psychiatry 2013; 202 (suppl 54): s36-40.

12 McGorry P, Bates T, Birchwood M. Designing youth mental health services for the 21st century: examples from Australia, Ireland and the UK. Br J Psychiatry 2013; 202 (suppl 54): s30-5.

13 Lamb C, Murphy M. The divide between child and adult mental health services: points for debate. Br J Psychiatry 2013; 202 (suppl 54): s41-4.

14 Royal College of Psychiatrists. No Health without Public Mental Health: The Case for Action (Position statement PS4/2010). Royal College of Psychiatrists, 2010. 